\title{
ESCOLA, ENSINO E APRENDIZAGEM: A CONTRIBUIÇÃO DE ANÍSIO TEIXEIRA À EDUCAÇÃO BRASILEIRA
}

\author{
Tatiana Polliana Pinto de Lima ${ }^{1}$
}

\section{RESUMO}

Este artigo pretende debater acerca dos conceitos de escola comum, homem comum, democracia, escola universal, educação comum, defendidos por Anísio Teixeira em seu livro Educação Não é Privilégio. Trata-se das primeiras considerações de uma pesquisa bibliográfica cujo principal objeto de análise foi a obra acima citada. Ao final considera-se que Anísio Teixeira é um liberal que defende a ideia de justiça social a partir da defesa de uma escola que seria a responsável por proporcionar a igualdade de oportunidades à todos os homens a partir de suas aptidões individuais.

Palavras-Chaves: Anísio Teixeira; Liberalismo; Educação Comum;. Escola Comum.

\section{SCHOOL, TEACHING AND LEARNING: ANÍSIO TEIXEIRA'S CONTRIBUTION TO THE BRAZILIAN EDUCATION}

\begin{abstract}
This article intends to discuss the concepts of common school, common man, democracy, universal school, common education, defended by Anísio Teixeira in his book "Education is not a privilege". These are the first considerations of a bibliographical research whose main object of analysis was the work aforesaid. At the end it is considered that Anísio Teixeira is a liberal who supports the idea of social justice coming from the defense of a school that would be responsible for providing equal opportunities to all men through their individual skills.
\end{abstract}

Keywords: Anísio Teixeira; Liberalism; Commom Education; Commom School.

"Só existirá democracia no Brasil no dia em que se montar no país a máquina que prepara as democracias. Essa máquina é a da escola pública."

(Anísio Teixeira)

\section{INTRODUÇÃO}

Ao concebermos um debate sobre o Ensino Primário público no Brasil Anísio Teixeira é um dos intelectuais que precisam ser estudados em virtude de suas defesas para com este segmento de ensino, bem como para com uma escola pública de qualidade. Pretendemos, portanto ter como objetivo do artigo a seguir: explicitar a concepção de educação no Ensino Primário defendida por Anísio Teixeira a partir do livro Educação Não é Privilégio. 
Este foi um livro cuja primeira edição foi publicada em 1957. Esta primeira publicação saiu com duas partes, a saber: Educação Não é Privilégio (1953) e A escola pública, universal e gratuita (1956). Posteriormente a partir da segunda edição mais uma parte foi acrescida: Educação e a formação nacional do povo brasileiro (cuja escrita iniciou-se em 1958).

O livro é um compêndio de vários escritos de Anísio Teixeira (A.T.), produzidos em momentos diferentes e o seu objetivo maior segundo palavras do autor é "fazer um esforço de análise e formulação do plano de reconstrução da escola brasileira" (1968, p. 8). Nesta mesma página cuja seção é intitulada Nota Explicativa A.T. alerta os leitores de que a obra deve ser lida no seu tempo presente, observando as datas e as circunstâncias em que as partes foram redigidas para que não haja anacronismos. É procurando seguir esta orientação que a partir deste momento o texto enfocará a perspectiva de educação presentes neste livro em Anísio Teixeira.

\section{A ESCOLA, O ENSINO E APRENDIZAGEM NA VISÃo DE ANÍSIO TEIXEIRA}

A obra Educação Não é Privilégio foi produzida em um momento de construção de um projeto de modernização para o Brasil e a educação estava no centro de discussão e debate. Por meio da educação e da escola institucionalizada, acreditava-se que a mentalidade de Brasil moderno, uno e indiviso estava se construindo. Neste mesmo contexto existe o debate sobre a escola pública e a democratização do acesso por parte das massas, cujo principal objetivo era ascender socialmente através da escola. O autor também coadunava com este pensamento quando defendia uma escola universal de base comum que seria responsável por dar a cada indivíduo a possibilidade de se tornar alguém na sociedade a partir do desenvolvimento de seus dotes inatos e de suas aptidões.

A existência ou não de dotes inatos ou aptidões é alvo de muitas discordâncias no âmbito das Ciências Humanas e Sociais. Não pode-se desconsiderar as abordagens biológicas/maturacionais, de aprendizagem social, cognitivas, psicanalíticas, socioculturais e bioecológicas. Todas estas possibilitam compreender os fenômenos do desenvolvimento humano que envolvem aspectos genéticos, sociais, biológicos, históricos e culturais. Não deve-se tão tranquilamente falar em desenvolvimento a partir de seus dotes inatos e aptidões individuais sem considerar a existência de um processo de desenvolvimento humano a partir de uma análise sociogenética e histórico cultural. Um intelectual que defendeu esta concepção foi Vigotsky (1998). Para este autor a essência de todo homem é um conjunto de todas as relações sociais deste homem a partir de sua interação com o meio social, cultural e histórico em que ele vive.

Neste contexto, para Vigotsky conceber o debate da educação sem conceber que o processo de aprendizagem e ensino envolve relações muito mais complexas é desconsiderar o sujeito e as relações envolvidas ao longo de seu desenvolvimento e da sua aprendizagem. Neste contexto a educação é concebida como um sistema processual, complexo e contraditório em que as relações existentes entre os docentes e os discentes e entre estes e a gestão da escola e as suas experiências de vida não podem ser desconsideradas.

Para Chaves (2000, p. 206) 
Os novos processos de trabalho e a complexidade tanto cultural quanto científica exigem que a mera liberdade se transforme em liberdade da inteligência e da investigação científica no campo político e social, eliminando, desse modo, a contradição entre o máximo da integração mecânica e o mínimo de integração social que essa própria sociedade desenvolveu. $\mathrm{O}$ resgate dessa equivalência estaria na crença de que a inteligência não é algo inato, mas precisa ser desenvolvida e cultivada por meio de uma educação intencional e sistemática. A escola seria, então, segundo essa visão, a instituição responsável por esse processo educacional, transformando velhos hábitos de pensar do homem que, preparado intelectualmente, adaptar-se-ia de maneira definitiva às demandas da sociedade contemporânea.

Assim, há uma contradição no pensamento do próprio A.T. quando na obra explicitada defende as aptidões inatas, mas também reconhece a importância da escola como instituição responsável pela formação do sujeito.

Mas, antes de dar continuidade ao debate acerca do pensamento de Anísio Teixeira contido na obra acima posta, a obra em si deve ser apresentada. Esta é constituída de três partes distintas. A primeira parte é intitulada: Educação Não é Privilégio. Refere-se a uma conferência pronunciada em 1953 na Escola Brasileira de Administração Pública da Fundação Getúlio Vargas. Neste texto A.T. discutirá alguns conceitos que irão permear toda a sua obra tais como: homem comum, educação comum, educação dual, cultural geral. O objetivo do texto é “... mostrar, tão imparcial e objetivamente quanto possível, o desenvolvimento da escola brasileira à luz dos conceitos e das forças que nela atuaram." (1968, p. 11)

Neste primeiro momento defende a tese de que a escola pública sempre foi elitista e seletiva e que a educação pública comum voltada para o homem comum precisa ser defendida. Como argumento coloca que a educação comum não é somente um postulado democrático, mas igualmente científico, trazendo à tona toda a mudança de pensamento ocasionado no mundo por ocasião do surgimento da ciência experimental em fins da Idade Média. Da ciência experimental surgiria a base para a construção da escola moderna. Segundo A.T. a ciência experimental

... nada mais é do que o conhecimento racional tornado fértil e fecundo, pela sua ligação com a realidade concreta do mundo e da existência. Toda uma nova filosofia do conhecimento se estabeleceu em oposição à fórmula grega de dualismo entre o racional e o empírico. O racional foi submetido à comprovação da experiência e se fez, na realidade, empírico. Efetivamente, as diferenças entre o experimental e o empírico passaram a ser antes de precisão de métodos, segurança e observação e de controle na verificação, do que de objeto ou de natureza. Na realidade, a diferença passou a ser antes de grau de segurança no conhecimento do que de natureza do conhecimento. (1968, p. 14-15)

Para A.T. a escola e a educação brasileira deveriam ser repensadas já que a educação dual, modelo instituído no Brasil a partir da influência da escola francesa encontrava-se em crise, visto que esta escola brasileira era arcaica e não se encontrava em sintonia com a educação moderna.

Anísio Teixeira afirmava nesta obra que 
a ideia de "educação comum", da escola pública americana ou da école unique francesa, não era nada disto. Não se cogitava de dar ao pobre a educação conveniente ao rico, mas, antes, de dar ao rico a educação conveniente ao pobre, pois a nova sociedade democrática não deveria distinguir, entre os indivíduos, os que precisavam dos que não precisavam de trabalhar, mas a todos queria educar para o trabalho, distribuindo-os pelas ocupações, conforme o mérito de cada um e não segundo a sua posição social ou riqueza $(1968$, p. 29)

Contudo, uma pergunta pode ser posta: quem iria estabelecer o mérito de cada um e quais os critérios para o estabelecimento destes méritos? Dar os louros a quem merece? Como estabelecer que os que não têm acesso aos bens culturais, importantes para o processo de desenvolvimento, terão as mesmas chances que aqueles que têm todo acesso a teatros, cinemas, informações, internet, jornais, etc...? Como estabelecer uma educação comum que não seria dual quando historicamente no Brasil, segundo Anísio Teixeira, alguns têm acesso aos denominados bens culturais responsáveis pela constituição do capital humano?

Somente para explicitar ao leitor, a Teoria do Capital Humano defendia a educação como sendo um bem cultural. Enquanto bem cultural seria acessível àqueles que possuíssem condições materiais de possuí-la. Este argumento faz cair por terra o discurso de uma educação comum (igualitária) em uma sociedade pautada na desigualdade econômica e social (sociedade tanto do contexto de produção da obra Educação Não é Privilégio de Anísio Teixeira, como anteriormente à esta e igualmente até os dias atuais). Germano (2011, p. 182) coloca:

Como tornar possível o pressuposto liberal de assegurar a igualdade escolar num quadro dominado pela apropriação diferencial da riqueza material? $\mathrm{Na}$ verdade, trata-se de uma estratégia que se propõe conforme a "teoria do capital humano" - a introduzir modificações na ordem econômica, sem efetuar transformações estruturais. Para tanto, é fundamental uma ampliação dos investimentos em educação, elevando assim a escolarização dos indivíduos e transformando-os, inclusive os trabalhadores, em capitalistas, à medida que adquirem "conhecimento e diversas habilidades que representam valor econômico" (Schultz, 1973:13)

Neste contexto há a defesa de que a distribuição de renda desigual ocorria em consequência da desigualdade na escolarização das pessoas, daí Anísio Teixeira defender uma escola de base comum para todos. Seria a percepção de que a educação igual proporcionaria uma sociedade mais igual em decorrência de todos serem preparados para o mundo do trabalho.

Nenhum país vive, porém, de um tal mandarinato intelectual, ainda que realmente capaz, o que não é o caso brasileiro, mas dos quadros numerosos e eficazes do trabalhador comum, formado na escola primária, dos quadros do trabalhador qualificado, treinado diretamente pela indústria e pelos cursos de continuação, dos quadros do especialista de nível médio preparado nos cursos médios, múltiplos e variados, e dos quadros de especialistas de nível alto, formados pela universidade e pelas escolas superiores.

A escola primária que irá dar ao brasileiro esse mínimo fundamental de educação não é, precipuamente, uma escola preparatória para estudos 
ulteriores. A sua finalidade é, como diz o seu próprio nome, ministrar uma educação de base, capaz de habilitar o homem ao trabalho nas suas formas mais comuns. Ela é que forma o trabalhador nacional em sua grande massa. É, pois, uma escola que é o seu próprio fim e só indireta e secundariamente prepara para o prosseguimento da educação ulterior à primária. (TEIXEIRA, 1968, p. 35)

Contudo, ao longo da leitura do capítulo podemos perceber que a ideia de escola comum se refere à escola homogênea.

Quando, na Convenção Francesa, se formulou o ideal de uma educação escolar para todos os cidadãos, não se pensava tanto em universalizar a escola existente, mas em uma nova concepção de sociedade em que privilégios de classe, de dinheiro e de herança não existissem, e o individuo pudesse buscar pela escola, a sua posição na vida social." (1968, p.12)

Para A. T. para se realizar o debate acerca da escola pública precisa-se entender a educação escolar antes das aspirações modernas de educação advindas com a Revolução Francesa. Considera esta como um marco que traz um novo estágio para a humanidade. "Antes desse período, toda educação escolar consistia na especialização de alguém, cuja formação já fora feita pela sociedade e em rigor pela classe a que pertencia nas artes escolares, que não eram mais que tipos de ofícios intelectuais e sociais." (TEIXEIRA, 1968, p.11).

Apesar de reconhecer que a escola é uma instituição que corporifica ideias e aspirações sociais, explicita ao leitor que a sociedade antes da Revolução Francesa formava homens no seio das castas ou classes as quais incorporavam a religião, a família e suas influências e pensamentos.

Outro conceito muito arraigado no pensamento de A.T. era o de escola universal. Para A.T. era uma instituição que iria dar a cada indivíduo a possibilidade de ascender social e economicamente na sociedade, o que nos remete à uma ideia iluminista de guiar alguém.

O homem teria então uma formação comum na escola, e depois se especializaria para atuar em uma sociedade democrática e moderna. Esta seria constituída “... com a criação da nova escola comum para todos, em que a criança de todas as posições sociais iria formar a sua inteligência, vontade e caráter, hábitos de pensar, de agir e de conviver socialmente." (TEIXEIRA, 1968, p. 12)

Há nesta obra de A.T. especificamente a discussão sobre a necessidade de mudanças na escola tradicional, visto que esta uniformizava. Contrário a este pensamento propunha que a nova escola deveria estar preparada para atender as vocações várias, aos ofícios vários e profissões que estavam nascendo na sociedade liberal e progressiva. Esta escola seria então prática, moderna e eficiente, concebida a partir de novas técnicas e processos novos. Esta escola seria a que possuiria um programa de atividades e não de matérias, iniciadora nas artes do trabalho e do pensamento reflexivo, ensinando o aluno a viver inteligentemente e a participar responsavelmente da sociedade. Mais uma vez afirmamos que não é, portanto, uma ideia de transformação, mas de adequabilidade participativa, de justiça social.

No bojo deste debate encontrava-se a sua preocupação em equilibrar os interesses individuais com os interesses coletivos (da sociedade), o equilíbrio entre 
liberdade e igualdade. A busca pela construção da democracia. Alvo da segunda parte do livro.

Na segunda parte do livro o objetivo é discutir a importância da educação para a construção da democracia. Ao longo do texto através de uma retrospectiva históric o autor mostra que ainda não se tem no Brasil uma democracia consolidada e defende que somente através da educação é que aquela será construída. Este capítulo é escrito em um momento em que o governo de Juscelino Kubitschek entrou para a história do país com uma gestão na qual se registrou o mais expressivo crescimento da economia brasileira. É ainda neste momento que A.T. conclama os educadores a darem o pontapé inicial em prol de uma modificação real na escola pública brasileira.

Para o autor a escola pública primária (defesa maior de seus escritos) seria uma escola de base comum, que serviria a ricos e pobres, seria uma escola onde privilégios de classe, de dinheiro e de herança não existissem. Este foi o maior legado, na sua visão, da Revolução Francesa, apesar de a própria França não ter conseguido implantar este ideal. Para A.T. os Estados Unidos com a sua educação pragmatista, prática foi quem conseguiu implementar este pensamento de ascensão social através da promoção de oportunidades iguais a todos. Isto teria feito os Estados Unidos se desenvolverem economicamente e se tornarem uma nação próspera economicamente. Contudo, "os [...] que se filiam a essa postura teórica omitem uma questão decisiva, a de que a escolarização desigual tem como substrato a desigualdade social, determinada pela apropriação privada da riqueza socialmente produzida." (GERMANO, 2011, p. 183)

Para A.T. a educação é o único meio capaz de transformar o povo em ator principal dos acontecimentos, seria a única forma de criar cidadãos capazes de cuidar do público, de participar ativamente da vida pública e de construir uma sociedade verdadeiramente democrática. É a ideia de justiça social, de reformas sociais sem necessariamente precisar haver uma revolução estrutural no seio da sociedade capitalista.

A unificação do sistema escolar, garantindo o direito de todos à educação, seria o passaporte para a constituição dessa sociedade verdadeiramente democrática, que distribuiria os indivíduos socialmente não com base em sua origem social, mas de acordo com o desenvolvimento de suas potencialidades.

A compreensão desse paradoxo, inerente à própria teoria liberal, faz com que Anísio Teixeira perceba que se num primeiro momento do liberalismo pensa-se em liberdade do indivíduo e a educação é uma necessidade social, num segundo momento, no entanto, o Estado precisa acompanhar as transformações sociais para consolidar o projeto liberal com uma face democrática, e a liberdade tem de ser social, porque ao ser convertida em dever do Estado, torna a educação um direito de cada indivíduo. Nesse sentido, um dos pontos nevrálgicos do liberalismo de Anísio Teixeira seria exatamente a necessidade de conversão da liberdade do indivíduo em direito de cada indivíduo participar de forma autônoma do jogo social, tendo como condição para essa participação o direito à educação. (CHAVES, 2000, p. 207)

A. T. tentou resolver um problema social e econômico com a expansão da escola pública e um currículo de base comum a ser implantado nesta escola não opondo indivíduo e sociedade, já que na sua visão o indivíduo somente existiria em sua plenitude por meio de sua convivência social. Na sua visão, a educação seria a responsável pela solução dos conflitos gerando uma estabilidade social. 
Contudo, mesmo defendendo um equilíbrio entre indivíduo e sociedade, defendendo a educação como propulsora da estabilidade social, A.T. nunca descartou a existência de haverem alunos mais capacitados do que outros. Explicitou esta ideia quando de sua defesa a respeito do conceito de cultura geral.

... ou teremos cultura geral como a mais alta expressão da cultura, como a praticam os filósofos, e só longos anos de estudos, altamente especializados, nos levarão a ela, ou teremos uma cultura geral popularizada, a ser dada pelos chamados vulgarizadores das ciências, das artes e das filosofias.

No primeiro caso, poderemos, com determinados alunos de alta capacidade, treiná-los no uso das ideias, familiarizá-los com o jogo dos conceitos matemáticos, científicos, literários e artísticos, e habilitá-los a ser especialistas nas ideias fundamentais com que a mente humana vem elaborando os seus extensíssimos conhecimentos experimentais, em todos os setores do saber humano. Estes seriam os estudiosos de cultura geral e, na realidade, filósofos das ciências, das artes, das letras e da religião.

Aos demais alunos, a cultura geral só poderá ser ministrada pelos livros de popularização da cultura. (TEIXEIRA, 1968, p. 21)

Neste sentido, como pensar uma educação comum e uma escola universal para que se possa construir uma democracia se já se concebe alunos com mais capacidades inatas do que outros? Assim, na concepção de Anísio Teixeira, somente uma escola de base comum resolveria os problemas sociais e capacitaria a todos para a sociedade na qual os sujeitos estão inseridos. A sua aproximação com John Dewey se apresenta. Para Dewey "as chances de realização da democracia estariam na possibilidade de a ciência irradiar o seu ethos para as instituições sociais, tornando os indivíduos, capacitados pelo conhecimento científico, aptos para participarem da vida social." (CHAVES, 2000, p. 205)

Na terceira parte do livro - Educação e a formação nacional do povo brasileiro Anísio defende a universalização do ensino público primário de qualidade, a partir de uma crítica feita à tradição escolar que imperou durante toda a primeira metade do século XX no Brasil. Igualmente apresenta o Plano Nacional de Educação do início da década de 1960 do qual foi relator e apresenta o Centro Educacional Carneiro Ribeiro (Escola-Parque) criado por ele e por sua irmã Carmem Teixeira (Psicóloga) no bairro da Liberdade em Salvador. A preocupação com a legislação ocorre, pois para A.T. as igualdades de oportunidades “... implicariam [na] elaboração de determinadas leis pelo Estado, a fim de que essa igualdade [fosse] assim garantida constitucionalmente.” (CHAVES, 2000, p. 208)

Os objetivos deste capítulo são:

- Propor a reforma do ensino brasileiro concebendo um novo modelo de ensino primário experimental, mas igualmente propedêutico voltado para a formação do homem comum.

- Nortear o leitor sobre a experiência prática da Escola Parque que seria a referência educacional para se pensar e implantar essa nova Escola, visto que para o autor uma educação de qualidade deveria ser voltada para um ensino primário que resolvesse os problemas de estratificação social e os desníveis econômicos da sociedade brasileira.

Neste sentido, a proposta educacional do Centro Educacional Carneiro Ribeiro almejava superar os elementos considerados impeditivos para o desenvolvimento de uma educação de qualidade apresentando soluções tais como: currículo integral e 
contextualizado, formação de professores de forma qualificada, qualificação para o mundo do trabalho.

Para isto afirmava:

Por isso mesmo, a escola já não poderia ser a escola dominantemente de instrução de antigamente, mas fazer as vezes da casa, da família, da classe social, e, por fim, da escola, propriamente dita, oferecendo a criança oportunidades completas da vida, compreendendo atividades de estudos, de trabalho, de vida social e de recreação e jogos. Para essa escola, precisava-se, sim, de um novo currículo, um novo programa e um novo professor. (1968, p. 129)

Ora, todo pensador e todo homem é fruto de seu tempo. Desta forma, A.T. foi influenciado sobremaneira pelos ideais de liberdade tão marcantes na sociedade moderna capitalista de seu tempo. Este pensamento nasce do liberalismo clássico o qual teoricamente concebe governos que possuem poderes definidos e limitados e à sociedade civil, por sua vez é dada uma ampla margem de liberdade. Neste sentido, A.T. afirma que esta ampla margem de liberdade seria construída através da escola universal de educação comum. Os poderes limitados do estado se tornam claros quando A.T. faz a defesa da descentralização da educação afirmando que

A descentralização, assim, contingência da nossa extensão territorial e de
nosso regime federativo e democrático, é hoje uma solução, além de
racional e inteligente - absolutamente segura. Tenhamos, pois, o
elementar bom senso de confiar no país e nos brasileiros, entregando-lhes
a direção dos seus negócios e, sobretudo, da sua mais cara instituição - a
escola, cuja administração e cujo programa deve ser de responsabilidade
local, assistida e aconselhada tecnicamente pelos quadros estaduais e
federais. (TEIXEIRA, 1968, p. 38)

Segundo Marilena Chauí em seu livro Brasil: mito fundador e sociedade autoritária este era o momento da construção da identidade nacional (concebida como harmonia e/ou tensão entre o plano individual e o social), do orgulho em ser brasileiro. É a formação da consciência nacional (coletiva) a partir da formação da consciência individual sobre ser brasileiro e consequentemente da consciência social do significado do ser brasileiro. É a emancipação política do indivíduo.

A partir desta concepção A.T. defende um ideal civilizatório nos trópicos (Brasil) a partir da construção de uma "grande cultura" brasileira, percebendo que haverá regionalismos que a diversificará, mas cujas aspirações em direção à formação de uma identidade nacional, de um país moderno e desenvolvido tanto cultural como tecnologicamente são unos em direção a construção de uma sociedade democrática.

Neste sentido, a escola deixaria de ser para poucos, para os homens devotados as atividades do espírito para ser de todos, do homem comum, que está em uma sociedade de trabalho científico e não empírico. O objetivo da escola seria então o de preparar trabalhadores para as três fases do saber no seu entender: pesquisa, ensino e tecnologia a partir do gosto específico, das escolhas "pessoais". Levaria em consideração a necessidade de todos.

a escola não mais poderia ser a instituição segregada e especializada de preparo de intelectuais ou "escolásticos", mas deveria transformar-se na agência de educação dos trabalhadores comuns, dos trabalhadores 
qualificados, dos trabalhadores especializados em técnicas de toda ordem e dos trabalhadores da ciência nos seus aspectos de pesquisa, teoria e tecnologia." (TEIXEIRA, 1968, p, 17)

A partir da identificação do mundo do trabalho agrícola e do trabalho fabril com o trabalho científico constituir-se-ia então a escola de ciência considerando o conhecimento científico. Ensino se faz então pela ação e pelo trabalho e "não somente pela palavra e pela exposição." Defendia a prática aliada à teoria.

No quesito aprendizagem reconhece a importância e influência dos estudos de psicologia do início do século XX que comprovaram que a aprendizagem verbal não era aprendizagem. Esta se dava a partir da experiência vivida e real, ou seja, prática. Para A.T. “... somente através da experiência vivida e real é que a mente aprende e absorve o conhecimento e o integra em formas novas de comportamento." (1968, p. 17). Era neste sentido, contra os métodos de aprendizagem utilizados na escola antiga que se reduziam a aulas, provas escritas e orais, memorização de conteúdos e tarefas de casa.

"regulares e sistemáticas são as formas arcaicas do ensino pela
"exposição oral" e "reprodução verbal" de conceitos e nomenclaturas,
mais ou menos digeridos por simples "compreensão", as quais dominam
me boa parte a escola primária e, esmagadoramente, a escola média,
sobretudo a secundária, e a maior parte das escolas superiores".
(TEIXEIRA, 1968, p. 18)

Ideias pautadas em um ensino-aprendizagem prático, vivido. A escola seria um meio para o indivíduo alcançar a sua plena participação na sociedade, tornando-o um cidadão ativo. A influência de Dewey, filósofo americano, pode aqui ser igualmente percebida. Este intelectual concebia a importância de se vivenciar várias experiências no ambiente escolar visando uma estimulação das aptidões individuais. Chaves (2000) afirma que

De acordo com Dewey (1956), a educação é que possibilitará o desenvolvimento das capacidades do indivíduo, tornando-o cidadão ativo e participativo. Acredita, ainda, que a educação, principalmente a escolar, garantirá o equilíbrio entre os vários elementos do ambiente social e as aptidões individuais [...] Procuraria auxiliá-los, por meio da cooperação, a desenvolver as aptidões naturais, estimulando-os, desde cedo, a vivenciar dentro do ambiente escolar as mais variadas experiências. (p. 205)

\section{CONSIDERAÇÕES FINAIS}

Para se construir a escola comum A. T. afirmava que se precisava de uma escola que tivesse as seguintes características:

1 - turno integral

2 - enriquecimento do programa com atividades práticas

3 - oportunidades de formação de hábitos da vida real.

4 - organização da escola como uma miniatura da comunidade.

Isto faria com que a escola se reconciliasse com a comunidade - sem o caráter dominante de escola propedêutica aos estudos ulteriores. Para isto a escola precisaria ser 
regional, enraizada no meio local, servida por professores da região, identificado com os costumes (currículo regional). Neste sentido, a municipalização da escola seria a alternativa mais viável (administração local, programa local, professor local).

Uma escola pública, primária, laica e de qualidade. Esta era a defesa de Anísio Teixeira. Mesmo que isto não significasse uma revolução educacional, mas uma justiça social.

\begin{abstract}
A escola primária que irá dar ao brasileiro esse mínimo fundamental de educação não é, precipuamente, uma escola preparatória para estudos ulteriores. A sua finalidade é, como diz o seu próprio nome, ministrar uma educação de base, capaz de habilitar o homem ao trabalho nas suas formas mais comuns. Ela é que forma o trabalhador nacional em sua grande massa. E, pois uma escola que é o seu próprio fim e só indireta e secundariamente prepara para o prosseguimento da educação ulterior à primária. Por isto mesmo, não pode ser uma escola parcial, nem uma escola somente de letras, nem uma escola de iniciação intelectual, mas uma escola sobretudo prática, de iniciação ao trabalho, de formação de hábitos de pensar, hábitos de fazer, hábitos de trabalhar e hábitos de conviver e participar em uma sociedade democrática, cujo soberano é o próprio cidadão." (TEIXEIRA, 1968, p. 35-36)
\end{abstract}

Analisando as palavras de A. T. se percebe que apesar do mesmo possuir algumas ideias de avanço em relação à educação brasileira, as influências positivistas e iluministas estão muito presentes no seu pensamento. Algumas expressões utilizadas pelo autor podem ser utilizadas a título de comprovação: "... é imprescindível certa precisão..." (1968, p. 11); “.... entendimento comum...” (1968, p. 11); “...progresso útil...” (1968, p. 11); “...forças de progresso...” (1968, p. 38); “...aspirações de civilização...” (1968, p. 38); “...progresso educacional..." (1968, p. 43). O ideal maior de A.T. é, portanto, o ideal civilizatório, de uma nação progressista objetivando a prosperidade econômica e social aos moldes americanos.

\title{
REFERÊNCIAS
}

ALMEIDA, Stela Borges de (org.) Chaves para ler Anísio Teixeira. Salvador: EGBA/UFBA, 1990.

CHAUÍ, Marilena. Brasil: mito fundador e sociedade autoritária. São Paulo: Ed. Fundação Perseu Abramo, 2001.

CHAVES, Miriam W. O Liberalismo de Anísio Teixeira. Cadernos de Pesquisa, n. 10, p. 203-211, jul. 2000.

FUNDAÇÃO Getúlio Vargas. Anísio Teixeira: a construção da educação brasileira. Brasília: MEC/ CAPES, [s.d].

FONTES, Solon Santana. Anísio Teixeira, um educador iluminista: premissas da modernidade no Brasil (1924-1970). Salvador: Instituto Anísio Teixeira, 2008. 
GERMANO, José W. Estado Militar e Educação no Brasil (1964-1985). 5. Ed. São Paulo: Cortez, 2011.

LIMA, Tatiana P. P. de; MARQUES, Cássio D.; PEREIRA, Eduardo T. Friedrich August von Hayek (1899-1992): da liberdade à Educação. Revista de Educação, v. V, n. 5, p. 101-114, out. 2002.

MONARCHA, Carlos (org.) Anísio Teixeira: a obra de uma vida. Rio de Janeiro: DP\&A, 2001.

ROCHA, João Augusto de Lima et al. Anísio em Movimento: a vida e as lutas de Anísio Teixeira pela escola pública e pela cultura no Brasil. Salvador: Fundação Anísio Teixeira, 1992.

RUGIU, Antônio S. Nostalgia do Mestre Artesão. Campinas: Autores Associados, 1998.

TEIXEIRA, Anísio. Educação não é privilégio. São Paulo: Companhia Editora Nacional, 1968.

VIGOSTSKY, Lev S. A formação social da mente: o desenvolvimento dos processos psicológicos superiores. São Paulo: Martins Fontes, 1998.

Notas

\footnotetext{
${ }^{1}$ Mestre em Educação pela UNICAMP. Doutoranda em Educação pela UFBA. Graduada em História pela UFRN. Graduanda em Pedagogia pela UNIFACS. Professora Assistente na UFRB. Coordenadora Institucional do PARFOR-UFRB. Coordenadora Institucional do LIFE-CAPES-UFRB. Coordenadora Estadual do GT Ensino de História-ANPUH-BA. Universidade Federal do Recôncavo da Bahia - UFRB email: tatyalima@yahoo.com
}

Recebido: abril/13 Aprovado: novembro/13 